\title{
Application of Entropy Weight Theory in Evaluation of Rainstorm Risk
}

\author{
Zhiguo $\mathrm{Ma}^{1}$, Wenqing $\mathrm{Li}^{2, *}$ and Jida Peng ${ }^{1}$ \\ ${ }^{1}$ Meteorological Science Institute in Fujian Province, Fuzhou, 350001, China \\ ${ }^{2}$ Fujian Institute of Tobacco Agricultural Sciences, Fuzhou, 350003, China \\ ${ }^{*}$ Corresponding author
}

\begin{abstract}
In order to study the effect of heavy rain on the growth of tobacco in Fujian Province tobacco planting area, it used the entropy weight theory that it computers the danger index of rainstorm by the torrential rain days and rainfall intensity as the evaluation index, and under the support of GIS technology storm disaster spatial distribution characteristics were analyzed. The results showed that: The rainstorm risk was mainly concentrated in the northwest mountains and southern minority region, mainly distributed in west of Sanming and the northern of Nanping. This study can provide data reference for agricultural disaster reduction.
\end{abstract}

\section{Keywords-rain days; rainfall intensity; rainstorm risk}

\section{INTRODUCTION}

In the southern part of China, many scholars have made a lot of research on the climate characteristics and causes of the rainstorm, and many achievements have been made in [1-5]. Tobacco cultivation in Fujian Province are mainly distributed in western inland region such as Nanping, Sanming and Longyan, is one of the main sources of local economy. The planting area of about 1 million acres in each year, accounting for about $6 \%$ of the national output [6]. Fujian has a mild climate, abundant sunshine, abundant rainfall, suitable for the growth of flue-cured tobacco, and is famous for its delicate fragrance, which has become one of the important bases of cigarette in China. Rainstorm is one of the main meteorological disasters, and the flood disaster causing by it is greatly influence on the tobacco production in Fujian. It often resulted in tobacco field water for a long time, the root vigor of tobacco plant decreased; root black and lower tobacco leaves turn yellow, the whole plant wilting and even death. Through analysing the historical meteorological data of Fujian tobacco growing areas. The characteristics of the distribution and change of heavy rain are studied, which provide the basis for the safe growth of tobacco and the meteorological disaster reduction.

\section{DATA AND METHODS}

\section{A. Sources of Data}

This article uses the number of days of precipitation of Fujian province day precipitation (20:00-20:00 value) according to the Fujian province meteorological bureau, the time period is 1971-2014 years, the data of the meteorological station site is 28 in the tobacco growing areas. Rainstorm day number is defined for $50.0 \mathrm{~mm}$ daily precipitation, the average rainfall intensity is defined as the ratio of the heavy rains and rain days.

\section{B. Integrated Risk Index}

The risk comprehensive index is a mathematical model of two meteorological variables: rainstorm day number and rainfall intensity. The first step is dimensionless processing of the original meteorological data to get the standard data, then according to the entropy value method to determine the weights of different meteorological index values, and finally to get comprehensive disaster index and divided into four disaster grade. According to occurred frequency of the different disaster grade, the use of GIS tool making the thematic map, researched the spatial and temporal distribution features of rainfall damage.

It is the most important to determine the weight of index in the process, at present the main methods of determining the weight are subjective and objective weighting method. Subjective weighting method is the most common expert scoring method, its advantage is clear concept and simple operation, but need to seek a certain quantity of experts of a profound experience to give score. Objective weighting method is the value evaluation of a judgment matrix to determine the index weight; the most commonly used entropy value method is to calculate by the index information utility value, the higher the value, the greater importance of the utility of the evaluation.

Entropy in information theory is measurement of a kind of system disorder degree, entropy weight coefficient method is widely used in the field of social and economic research, its objectivity is strong, can overcome the human subjectivity and determine the weight indicator variable information overlap. If in the decision an index of the utility value is bigger, the information entropy is smaller, the indicators provide the more information, the index weight is bigger also; the utility value of indicators is smaller, the index weights are smaller. So we can accord the utility value of indicators, using the information entropy to calculate the weight of each index. Considering objectivity, weight coefficient was definite by the entropy value method [7-8].

Comprehensive risk index calculation steps are as follows:

(1) Constructing index matrix of original data: 
Matrix sample is $\mathrm{m}, \mathrm{X}_{\mathrm{ij}}$ is for the $\mathrm{j}$ index value of the I year.

(2) Data dimensionless processing:

Positive evaluation index for:

$$
\mathrm{Yij}=(\mathrm{Xij}-\mathrm{Xjmin}) /(\mathrm{Xjmax}-\mathrm{Xjmin})
$$

Reverse evaluation index for:

$$
Y i j=(X j m a x-X i j) /(X j m a x-X j m i n)
$$

Where $Y_{i j}$ is for data of dimensionless processing, $X_{i j}$ is standard value for index statistics, $X_{j \max }, X_{j \min }$ respectively during the period of tobacco transplant the same index of the maximum and minimum value, $I$ for the $I$ sample, $j$ for the $j$ index.

(3) Calculation value $P_{i j}$ of $j$ indicators in the I year:

$$
\sum_{\mathrm{Pij}=\mathrm{Yij} /}^{i} \mathrm{Yij}_{1}
$$

(4) Calculation information entropy Ej of $\mathrm{j}$ indicators:

$$
\mathrm{Ej}=-\mathrm{k} \sum_{1}^{i} \text { Pijln Pij }
$$

Among them, $\mathrm{k}=1 / \mathrm{lnm}$, and assume that when $\mathrm{P}_{\mathrm{ij}}=0$, $\mathrm{P}_{\mathrm{ij}} \ln \mathrm{P}_{\mathrm{ij}}=0$. The constant of information entropy only have relation with matrix sample size $\mathrm{m}$. The information entropy formula is output source of each message provided by the average amount of information; income sources of entropy have uncertainty. For a disordered information systems, degree of order to 0 , entropy value is the largest, $\mathrm{E}=1$; a sample in a fully disordered distribution state, $0<\mathrm{E}<1$.

(5) Calculation utility value $D_{j}$ of the $j$ indicators:

$$
\mathrm{Dj}=1-\mathrm{Ej}
$$

(6) Calculation weight $\mathrm{W}_{\mathrm{j}}$ of $\mathrm{j}$ indicators:

$$
W j=D j / \sum D j
$$

(7) Comprehensive risk index formula:

$$
\mathrm{R}=\mathrm{aX}+\mathrm{bY}
$$

On all the indexes weighted summation, rainstorm comprehensive risk index value is calculated. The $\mathrm{R}$ is for comprehensive risk index, $\mathrm{a}, \mathrm{b}$ is for weight coefficient, $\mathrm{X}, \mathrm{Y}$ is separately the standard of value rainstorm day number and rainstorm intensity.

(8) Rainstorm risk grade:
According to the comprehensive risk index $\mathrm{R}$, the rainstorm risk type is divided into light, middle, heavy and extreme four grades that affect the tobacco growth, each level of risk index value $\mathrm{R}$ see table 1 .

TABLE I. THE RAINSTORM RISK GRADES OF TOBACCO PLANTING PERIOD

\begin{tabular}{|c|c|c|c|c|}
\hline Risk grades & Light & Middle & Heavy & Extreme \\
\hline R & $0 \leq \mathrm{R}<0.25$ & $0.25 \leq \mathrm{R}<0.50$ & $0.50 \leq \mathrm{R}<0.75$ & $0.75 \leq \mathrm{R}$ \\
\hline
\end{tabular}

\section{RESUlTS AND ANALYZES}

Fig. 1 is the spatial distribution of the rainstorm risk in the whole growth period of tobacco planting areas in Fujian province. It can be seen from that: the rainstorm risk index was the highest in the 90 s of the 20th century, the following in early twenty-first Century (2001-2010), the minimum of 1970s.

In 1970s, the rainstorm risk Index of Fujian tobacco planting area is generally low, the distribution range is $0-0.6$, the average value is 0.22 , which belongs to the low risk age.

In the 80 's, the scope of rainstorm risk index in tobacco growing areas is $0.17-0.67$, with an average of 0.33 . The rainstorm hazard ratio has been expanded in the 70 's, and the low risk areas are concentrated in the middle part of the eastern region, and only the minimum area of the northern part of the region is in danger of heavy rain. Overall, in the 80's, most of the major areas of tobacco growing areas were in moderate degree of risk.

In the 90's, the scope of rainstorm risk index in tobacco growing areas was $0.24-1.1$, with an average of 0.64 . As can be seen from the figure, the storm is the biggest risk of a period of time, only one site is mildly dangerous, heavy rain and low risk areas concentrated in the northern region of the east side of the region. Other regions with a high degree of above, especially in the central region of the western region is more than 0.75 , is a very high risk areas.

In early twenty-first Century (2001-2010), the scope of the rainstorm risk Index in the tobacco planting area is $0.37-0.81$, and the average value is 0.58 . In all storm danger stage, is second only to the 90's a high risk of the times. Extremely high risk areas are located in the middle of the eastern region, the other moderate risk is a strip from the south to the north, and the two sides are highly dangerous area.

In 2011-2014, the range of rainstorm risk index in tobacco planting area is $0.06-0.69$, and the average value was 0.41 . The rainstorm risk of low value area is located in the south west region, belonging to slight danger; in northern area, the southern part of the distribution of high risk areas, other areas is to moderate risk.

From the point of view of 1971-2014 annual average value of, Fujian tobacco planting area of the rainstorm risk mainly concentrated in the northwest mountains and southern minority region, mainly distributed in Sanming and west of Nanping in the northern region. The annual average value of 
the rainstorm disaster risk index is 0.44 , the maximum value is 0.57 , which appears in Ninghua, the minimum value is 0.33 , which appears in Guangze.
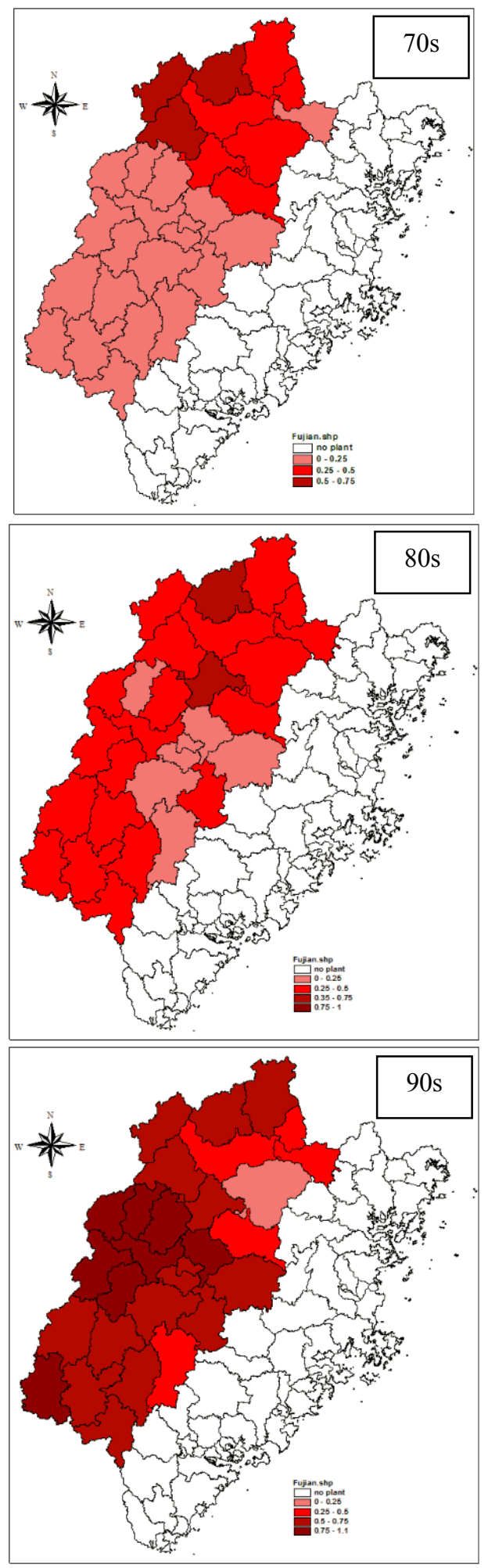
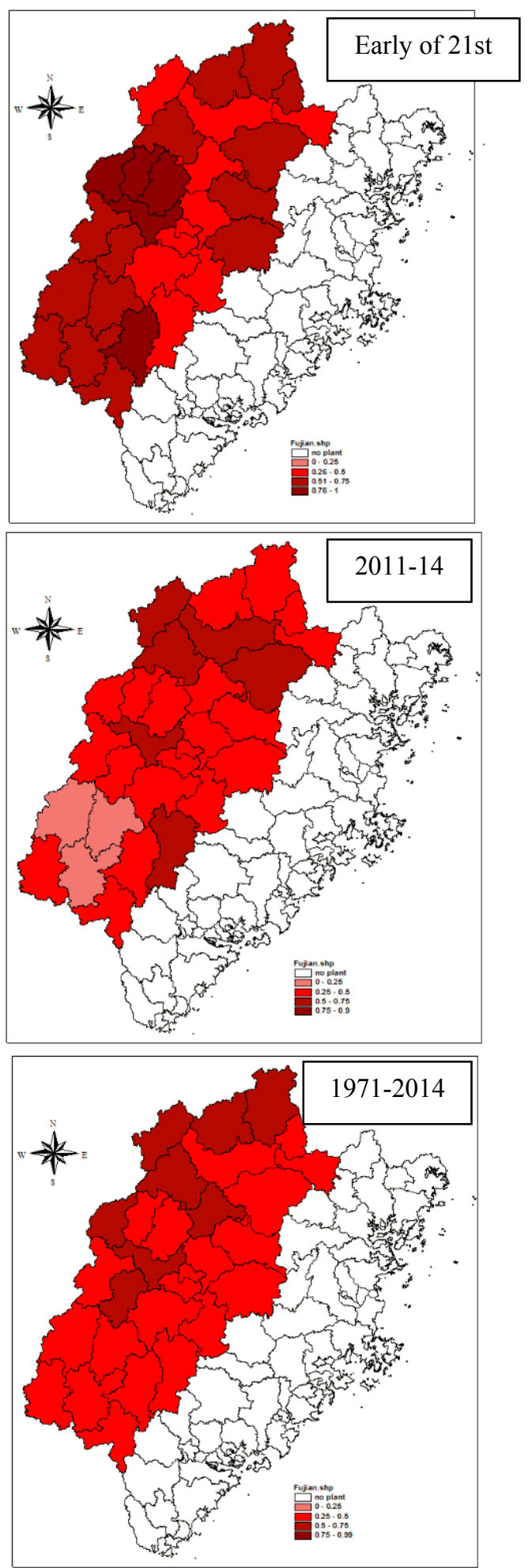

FIGURE I. THE SPATIAL DISTRIBUTION OF THE RAINSTORM RISK DURING THE WHOLE GROWTH PERIOD OF TOBACCO PLANTING AREAS IN FUJIAN PROVINCE 


\section{CONCLUSIONS AND DisCUSSIONS}

\section{A. Conclusion}

In this paper, the weather data of the rainstorm rain days and rainstorm intensity were as the evaluation index of the 1971-2014 in Fujian Province tobacco planting area of 28 stations, and using right theory and method that the rainstorm risk index computed, and under the support of GIS technology the rainstorm disaster spatial distribution were analysis. Main conclusions are: From the point of view of the average for many years, the rainstorm risk mainly concentrated in the northwest mountains and southern minority region, mainly distributed in Sanming and west of Nanping in the northern region. The risk index is the highest in 1990s and 2010s, the lowest in the 70's.

\section{B. Discussion}

The division of the risk level of the rainstorm, only from the perspective of climate, in the future should be combined with the actual impact on the growth and development of tobacco crops to further differences. When the rainfall reaches a certain threshold, the field tobacco crops flooded, and the effect of causing no production or production is the same. Of course, the drainage effect of locations is different, so the rainstorm risk is different.

In this paper, we only consider the risk of a single rainstorm, but in reality, the precipitation process is very complex, even if it is a single rainstorm, the use of time is also different, the shorter the time, the greater the harm. If several days of continuous precipitation process and then a rainstorm caused by the threat of more big, because the soil is saturated and cannot accommodate more precipitation; if pre drought, the soil is lack of water, the threat caused by torrential rain is relatively very small, and sometimes can be neglected. More data are needed to better define the risk of heavy rains on agricultural production. The division of the risk of heavy rain, the agricultural disaster reduction or have a certain practical significance.

\section{ACKNOWLEDGMENT}

This paper is funded by: China National Tobacco Corp of Fujian province science and technology projects (2014) 184.Fujian province meteorological bureau youth science and technology special project (q201206).

\section{REFERENCES}

[1] Xu Guiyu, Yang Xiuqun. Statistical analysis of some climatic characteristics of Rainstorm in South China [J]. Study on climate and environment, 2002, 7 (4): 447-456.

[2] Yu Gongmei. Climate characteristics of precipitation of South China in recent 40 years [J]. Journal of tropical meteorology, 1996, 2 (3): 252-256.

[3] Zheng Bin, Liang Jianyu, Lin Ailan, et. During pre rainy season in South China frontal rainfall and summer monsoon precipitation I. division date determination [J]. Atmospheric science, 2006, 30 (6): 1207-1216.

[4] Li Jiangnan, Wang Anyu, Meng Weiguang, et al. The climatic characteristics of precipitation in the pre flood season and post flood season in Guangdong province [J]. Journal of Zhongshan University (NATURAL SCIENCE EDITION), 2002, 41 (3): 91-94.
[5] Wang Qianqian, Deng Liping. Anomalous characteristics of Precipitation Anomalies over the 4 - 6 period before flood season in Southern China and its relationship with the sea surface temperature in China [J]. Journal of tropical meteorology, 2002, 18 (1): 45-55.

[6] Li Hongmei, Zhou Tianjun, Yu Rucong. Nearly forty years in eastern China change characteristics analysis of summer precipitation [J]. Atmospheric science, 2008, 32 (2): 358-370.

[7] Zhang Linying, $\mathrm{Xu}$ Songjun. A comprehensive evaluation of the nature reserve based on entropy weight in the Pearl River Delta [J]. Journal of ecology, 2011,31 (18): 5341-5350.

[8] Huo Zhiguo, Li Shikui, Wang Suyan, et al. Study on the risk assessment technique and its application of main agro-meteorological disasters [J]. Journal of natural resources, 2003,18 (6):692 -701. 